\title{
Effect of cold temperature on the length of incubation of Chamaeleo chamaeleon
}

\author{
Carmen Díaz-Paniagua
}

\begin{abstract}
Common chameleon eggs spend the first months of incubation at low temperatures. I incubated eggs of different clutches at $25^{\circ} \mathrm{C}$ in four treatments with respectively $0,84,119$ and 149 days of initial cold period $\left(\right.$ at $\left.14^{\circ} \mathrm{C}\right)$. Treatments with longer cold periods had longer total incubation but shorter periods of incubation at $25^{\circ} \mathrm{C}$. Eggs which did not experience initial cold period showed low synchronization at hatching. Hatchling body mass and length were influenced by the length of the cold period. Hatchlings were largest and heaviest for cold periods of intermediate length which had similar duration than the cold period experienced by eggs in nature. These results suggest that the cold torpor period of Common chameleon embryos contributes to optimization of development and growth, and synchronizes hatching.
\end{abstract}

\section{Introduction}

Reptiles exhibit several mechanisms of embryonic developmental arrest, which allow them to prolong the egg stage. Among these mechanisms, diapause is not dependent on incubation temperature, while cold torpor is sustained by incubation at low temperatures, and development resumes when temperatures are again favourable for development (Ewert, 1985, 1991). These mechanisms permit fall-nesting species to lay their eggs in cold seasons. During winter, eggs exhibit slow or no development until spring or summer conditions favour development (Ewert, 1985). The developmental arrest is known to occur in several turtle species laying eggs in autumn or winter (Ewert and Wilson, 1996; Booth, 2000), in chameleons (Bons and Bons, 1960; Andrews and Donoghue, 2004), and have been hypothesized for other species having very long incubation (see review in Ewert, 1991 and in Andrews, 2004) as Tuataras (Thompson et al., 1996).

In contrast to the general pattern in Mediterranean reptiles, Common chameleons (Chamaeleo chamaeleon) have autumnal oviposition and a very long incubation period (see Bons and Bons, 1960; Blasco et al., 1985; Díaz-Paniagua

Estación Biológica de Doñana-CSIC, Apdo 1056, 41080 Sevilla, Spain e-mail: poli@ebd.csic.es et al., 2002). Eggs experience the first months of incubation during the wettest season, then continuing during a cold winter period and hatch in summer approximately 10 months after oviposition. Common chameleons were among the first reptile species for which diapause has been described. Eggs incubated at $25^{\circ} \mathrm{C}$ were found to persist in gastrulation for six weeks (Ewert, 1985). Bons and Bons (1960) reported that oviposition occurred in a pregastrulation stage, which is followed by a period with very slow or no development. They found that eggs incubated at $25^{\circ} \mathrm{C}$ did not start differentiation until February (four months after oviposition).

Incubation temperatures in natural nests remain below $20^{\circ} \mathrm{C}$ for at least the last months of fall and the whole winter, gradually rising from March onwards, reaching values around $30^{\circ} \mathrm{C}$ from June to hatching (see fig. 1). In a previous study, in which eggs were incubated with an initial cold period, we observed that eggs doubled their mass during the first months, corresponding with the phase of arrested development (Díaz-Paniagua and Cuadrado, 2003). In the present study, Common chameleon eggs were incubated in the laboratory with different initial cold periods with the aim of analysing the importance of the period of developmental arrest on the duration of incubation and development and on the quality of hatchlings. 


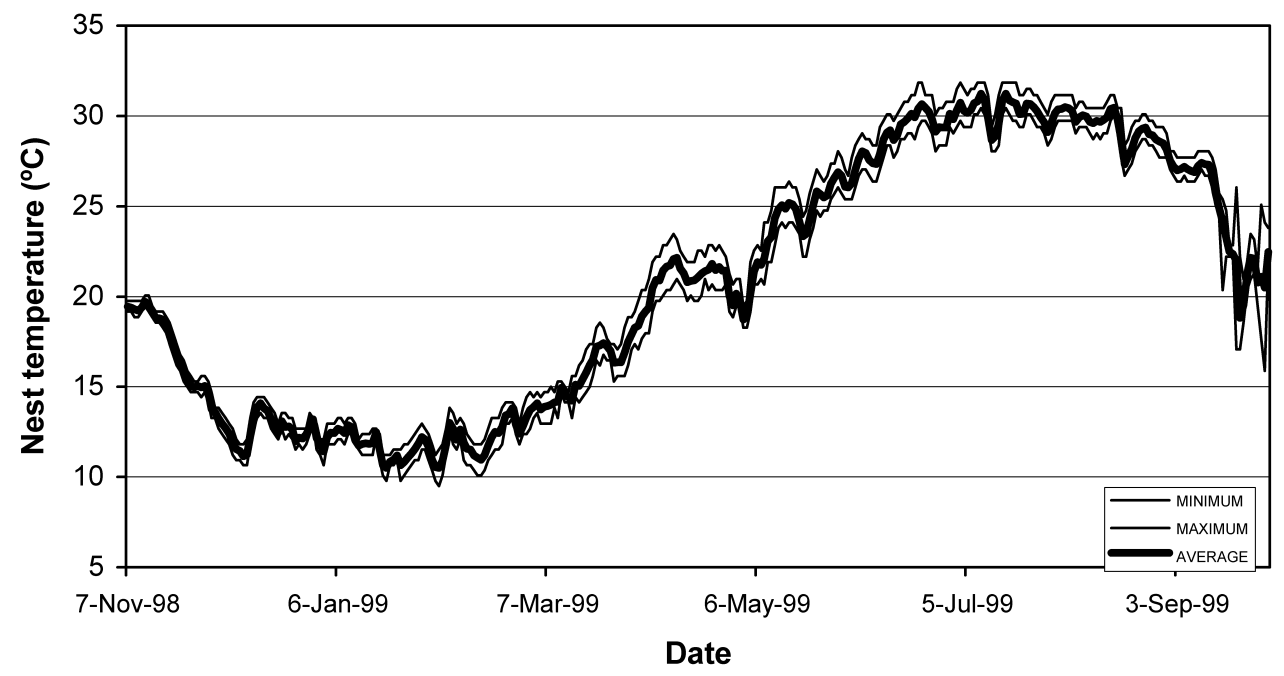

Figure 1. Incubation temperature in a natural Common chameleon nest from Southern Spain from November 1998 to September 1999.

\section{Material and methods}

I collected chameleon eggs from seven nests in November 1998, at Rota (Cádiz province in southern Spain). After transporting them to the laboratory, I weighed them to determine initial egg mass. Eggs were completely buried in vermiculite for incubation at an approximated water potential of $-150 \mathrm{kPa}$ (the vermiculite was moistened with $1.125 \mathrm{~g}$ of water/g, after Packard et al., 1987). They were distributed in 12 sealed plastic boxes, each one containing seven eggs, one from each clutch. Because one clutch had only 10 eggs, one box contained only six eggs and another box contained two eggs from the same clutch. I used four treatments with $0,84,119$ and 149 days of initial cold period, each one including three replicates. The experiment started on 9 November 1998. In the first treatment (T1) eggs were incubated at $25^{\circ} \mathrm{C}$ from the first day until hatching; in the second treatment (T2) they were kept at $14^{\circ} \mathrm{C}$ until $1^{\text {st }}$ February and then at $25^{\circ} \mathrm{C}$ until hatching; in the third treatment (T3) eggs were incubated at $14^{\circ} \mathrm{C}$ until $8^{\text {th }}$ March, then continuing at $25^{\circ} \mathrm{C}$ until hatching; and in the fourth treatment (T4) they were kept at $14^{\circ} \mathrm{C}$ until $7^{\text {th }}$ April and then incubated at $25^{\circ} \mathrm{C}$ until hatching. The length of the cold period in $\mathrm{T} 3$ was the most similar to the cold period in natural nests (see fig. 1).

I shifted the position of the boxes within incubators every week to randomise the possible gradients of temperature. I replaced moistened vermiculite in the boxes every two months, recording egg mass at that time. Around the hatching time, boxes were examined frequently in order to detect the exact date of hatching.

I considered the total incubation period as the time from placement of eggs in vermiculite to pipping (the day in which shell breakage occurred). The time from the day on which an egg began incubation at $25^{\circ} \mathrm{C}$ to the day of pipping is referred to as the incubation period at $25^{\circ} \mathrm{C}$. Body mass $( \pm 0.01 \mathrm{~g})$ and the snout-to-vent length $(\mathrm{SVL}, \pm 0.1 \mathrm{~mm})$ of hatchlings were recorded on the day of hatching.
Incubation temperatures were recorded in several nests in the same area with Onset Stowaway data loggers which recorded the temperature every 60 minutes. Figure 1 illustrates the variation of temperature recorded in one of these nests.

Differences in egg mass (after log-transformation) among clutches was tested with ANOVA. Because the duration of $25^{\circ} \mathrm{C}$ incubation periods had heterogeneous variances, their differences were tested using non-parametric KruskalWallis tests, and then all pairs of treatments were compared with Mann-Withney tests. Differences in egg mass increase, SVL and body mass of hatchlings among treatments were analysed through ANCOVA, using initial egg mass as the covariate, treatment as the fixed factor, and clutch as a random factor. The relationships of hatchling length and mass to egg variables and length of periods were examined using Pearson product-moment correlation.

\section{Results}

Overall hatching success was $96.4 \%$. One T3 egg died during the cold period and one T1 egg and one T4 egg died, during the incubation at $25^{\circ} \mathrm{C}$. Initial mass differed among clutches (ANOVA: $F_{6,73}=120.57, P<0.001$ ), because the egg mass in two of the seven clutches was greater than in the remainder (post-hoc Tukey test, $P<0.005$ ).

The periods of incubation at $25^{\circ} \mathrm{C}$ were significantly different among treatments (KruskalWallis ANOVA: $H=74.3, P<0.001$ ), and even in paired comparisons of all treatments 
Table 1. The mean lengths of total incubation period and of incubation at $25^{\circ} \mathrm{C}$ (mean \pm standard deviations) and dates of hatching for eggs of the four treatments with different lengths of an initial cold period.

\begin{tabular}{lcccc}
\hline Treatment & Cold period (days) & Dates of first and last hatching & Total incubation (days) & Incubation at 25 ${ }^{\circ} \mathrm{C}($ days) \\
\hline T1 & 0 & 29 April-31 May & $183.3 \pm 8.92$ & $183.3 \pm 8.92$ \\
T2 & 84 & 26 June-2 July & $231.7 \pm 1.71$ & $147.7 \pm 1.71$ \\
T3 & 119 & 20 July-26 July & $255.4 \pm 1.70$ & $136.4 \pm 1.70$ \\
T4 & 149 & 30 July-10 August & $266.6 \pm 2.41$ & $117.6 \pm 2.41$ \\
\hline
\end{tabular}

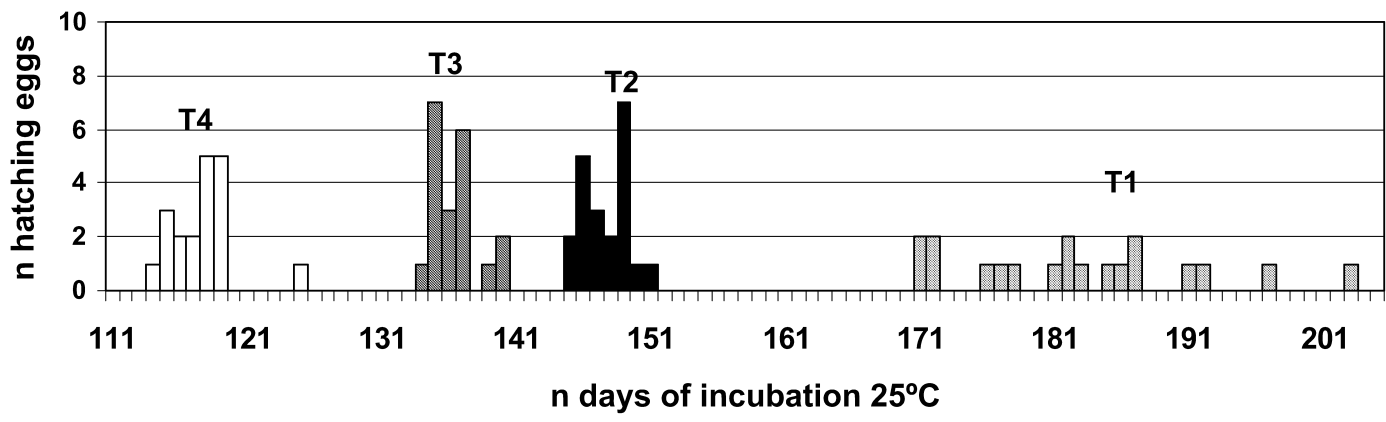

Figure 2. Number of eggs hatched per day after incubation at $25^{\circ} \mathrm{C}$. T1: no days of cold temperature; T2: 84 days of cold period; T3: 119 days of cold period; T4: 149 days of cold period.

(Mann-Whitney tests: $P<0.0001$ in all comparisons). Eggs of T1 also were less synchronised at hatching than eggs of the other treatments (table 1, fig. 2).

Changes in egg mass throughout incubation are shown in fig. 3. The values recorded in April were the last egg masses obtained for $\mathrm{T} 1$ and T2. There were significant differences between all treatments (table 2). T1 eggs achieved significantly heavier mass than eggs of other treatments, while egg masses did not differ significantly between T2 and T3 (post-hoc Tukey tests: $P=0.379$ ). The last egg mass obtained before hatching (comparing the egg mass recorded in April (T1 and T2) with mass in July of T3 and T4) also differed significantly among treatments (table 2). Finally, eggs of T3 and T4, after a longer incubation had higher mass than eggs of T1 and T2 (table 2, fig. 3). The effect of the clutch identity was only detected in comparisons of April egg mass, while in final egg mass this effect was not significant, although interaction of both variables had a significant effect (table 2).

Hatchling length was significantly affected by treatments and by clutch identity (table 2 ).

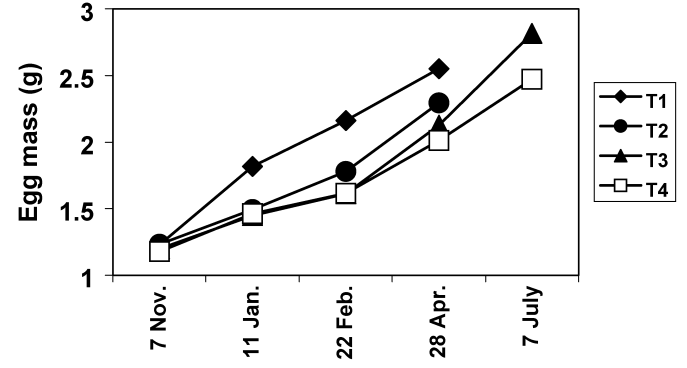

Figure 3. Variation throughout the incubation period of the average mass of Common chameleon eggs in the four different treatments: T1: no days of cold temperature; T2: 84 days of cold period; T3: 119 days of cold period; T4: 149 days of cold period.

The largest hatchlings came from $\mathrm{T} 2$ and $\mathrm{T} 3$. Hatchling body mass was also affected by the treatments, but was not affected by clutch identity (table 2). The hatchlings with heaviest mass were incubated in T3 (fig. 3), although these hatchlings were not those of greatest length.

Hatchlings from eggs of greater initial mass were heavier and longer ( $r_{\text {body mass }}=0.61$, $\mathrm{r}_{\mathrm{SVL}}=0.32 ; P<0.05$ in both cases). The relationship with body mass was observed independently in every treatment. However, the relationship with SVL was observed only in T1. 
Table 2. Results of the Analysis of Covariance on the effect of the cold period and clutch identity on the Egg mass in April and before hatching (Final), and the hatchling length and mass.

\begin{tabular}{|c|c|c|c|c|}
\hline Dependent variable & Source of variation & d.f. & $F$ & $P$ \\
\hline \multirow[t]{3}{*}{ April egg mass } & Cold period & 3,51 & 61.51 & $<0.001$ \\
\hline & Clutch & 6,51 & 3.73 & $<0.05$ \\
\hline & Cold period*clutch & 18,51 & 0.88 & 0.457 \\
\hline \multirow[t]{3}{*}{ Final egg mass } & Cold period & 3,51 & 16.89 & $<0.001$ \\
\hline & Clutch & 6,51 & 1.27 & 0.318 \\
\hline & Cold period*clutch & 18,51 & 4.78 & $<0.001$ \\
\hline \multirow[t]{3}{*}{ Hatchling length } & Cold period & 3,51 & 5.53 & $<0.01$ \\
\hline & Clutch & 6,51 & 8.44 & $<0.001$ \\
\hline & Cold period*clutch & 18,51 & 1.06 & 0.419 \\
\hline \multirow[t]{3}{*}{ Hatchling mass } & Cold period & 3,51 & 5.19 & $<0.05$ \\
\hline & Clutch & 6,51 & 0.69 & 0.660 \\
\hline & Cold period*clutch & 18,51 & 0.633 & 0.856 \\
\hline
\end{tabular}

\section{Discussion}

All eggs incubated without a cold period hatched within a wider time interval than eggs with an initial cold period. This suggests that Common chameleon eggs experienced an initial diapause followed by a period of cold torpor, with low or no development during the cold season. Arrested embryonic development during autumn and winter allows chameleon eggs to overwinter within the nests and continue development during the late spring and summer. Incubation at $25^{\circ} \mathrm{C}$ was longer in eggs which did not experience initial cold period than in eggs experiencing treatments with cold period, but the latter showed a higher synchronization of hatching. These results suggest that the initial diapause described for Common chameleon eggs may be associated with a cold torpor period during the fall and winter months. The fact that incubation at $25^{\circ} \mathrm{C}$ was shorter after longer cold periods suggests that development was not completely arrested during the cold period. The longer incubation at $25^{\circ} \mathrm{C}$ in $\mathrm{T} 1$ includes the six weeks of initial diapause (after Ewert, 1985), which is not included in the incubation period at $25^{\circ} \mathrm{C}$ of the other treatments. The wider range of days to hatching observed in T1 eggs may be a consequence of irregular duration of diapause independent of incubation temperature (Ewert, 1985). Eggs of other treatments continuing incubation in a cold torpor period started or accelerated development in response to the elevation of incubation temperature, which may have synchronized the eggs within each treatment.

Reptiles with egg diapause are characterized by a higher variance in the duration of incubation period than non diapausing species (Ewert, 1985). In Chelodina expansa, a turtle having two periods of diapause, Booth (2000) found that eggs within a clutch broke the first diapause asynchronously and so hatched over longer period of time. However, experimenting with a variety of cold periods, Booth (2002) observed that in treatments with eggs incubated at $28^{\circ} \mathrm{C}$ after being held at $18^{\circ} \mathrm{C}$, all eggs had arrested development in the secondary diapause at the same developmental stage, and that the increase in incubation temperature could be a mechanism by which breaking of this arrest was synchronized within a clutch. The cold period may therefore have an effect of synchronizing hatching. Within the same area, embryo development may respond to similar environmental temperature, which could also synchronize eggs from different clutches. In the case of our chameleons, this synchronization is usually observed in the field, where hatchling emergences are also concentrated in a short number of days, usually in August.

During the period of developmental arrest, eggs increased in mass by taking up water from the nest environment. Eggs without a cold period had a higher increase in egg mass during 
Table 3. Means and standard deviations of snout to vent length $(\mathrm{mm})$ and body mass $(\mathrm{g})$ of Common chameleon hatchlings incubated under the four different treatments.

\begin{tabular}{lcccc}
\hline & T1 & T2 & T3 & T4 \\
\hline Snout-vent length $(\mathrm{mm})$ & $31.75( \pm 0.10)$ & $32.87( \pm 1.07)$ & $32.64( \pm 1.21)$ & $31.93( \pm 1.74)$ \\
Body mass $(\mathrm{g})$ & $1.18( \pm 1.15)$ & $1.20( \pm 0.08)$ & $1.25( \pm 0.11)$ & $1.16( \pm 0.08)$ \\
\hline
\end{tabular}

most of the incubation period than eggs experiencing a cold period. This is explained by the effect of temperature on the water absorption by the eggs, as increased temperature favours the exchange of water vapour across the egg shell (Packard and Packard, 1988; Ackerman, 1991; Packard, 1991). However, eggs with a longer cold period eventually gained more mass during their longer incubation. In a previous study, both constant laboratory incubation conditions and maternal identity affected body size and mass of chameleon hatchlings (Díaz-Paniagua and Cuadrado, 2003). In the present experiment, only body length was affected by maternal identity. Hatchling body mass was independent of maternal influence, possibly because more water was absorbed during longer incubation periods compensating for initial differences in egg mass. This is confirmed by the fact that this relation was mainly observed in the treatment with shorter cold period. The longest hatchlings were obtained in treatments including four (T2) and five (T3) months of cold period. Eggs from $\mathrm{T} 3$ were also the heaviest hatchlings, suggesting that they probably had the most efficient metabolism during development. Hatchlings from $\mathrm{T} 4$ probably did not reach such a large body length and mass because they developed in a shorter period. The period of cold torpor in T3 was similar to the cold period of field nests. The larger size and presumably best quality of these hatchlings suggests that eggs of Common chameleons are adapted not only to sustain an obligatory long incubation, including periods of slow or no development, but also that their development is optimised for a long period of arrest or low development, which synchronizes hatching.
Acknowledgements. I thank J. Gómez Ruiz for field assistance. The manuscript was substantially improved after the comments of R.M. Andrews, R.A. Avery and an anonymous reviewer. DGICYT (Ministerio Ciencia y Tecnología PB97-1162) and Junta de Andalucía (Consejería de Medio Ambiente and Consejería de Educación y Cultura RNM 128) provided funds and permits for this study.

\section{References}

Andrews, R.M. (2004): Embryonic development. In: Reptilian incubation: environment, evolution, and behaviour, p. 75-102. Deeming, D.C., Ed., Nottingham, Nottingham University Press.

Andrews, R.M., Donoghue, S. (2004): Effects of temperature and moisture on embryonic diapause of the Veiled chameleon (Chamaeleo calyptratus). J. Exp. Zool. 301A: 629-635.

Ackerman, R.A. (1991): Physical factors affecting the water exchange of buried reptile eggs. In: Egg Incubation: Its Effects on Embryonic Development in Birds and Reptiles, p. 193-218. Deeming, D.C., Ferguson, M.W.J., Eds, Cambridge, Cambridge University Press.

Blasco, M., Cano, J., Crespillo, E., Escudero, J.C., Romero, J., Sánchez, J.M. (1985): El camaleón Común (Chamaeleo chamaeleon) en la Península Ibérica. Madrid, Ministerio de Agricultura, Pesca y Alimentación, Instituto Nacional para la Conservación de la Naturaleza.

Bons, J., Bons, N. (1960): Notes sur la reproduction et le développement de Chamaeleo chamaeleon (L.). Bull. Soc. Sci. Nat. Phys. Maroc 40: 323-335.

Booth, D.T. (2000): Incubation of eggs of the Australian broad-shelled turtle, Chelodina expansa (Testudinata: Chelidae), at differents temperatures: effects on pattern of oxygen consumption and hatchling morphology. Australian J. Zool. 48: 369-378.

Booth, D.T. (2002): The breaking of diapause in embryonic broad-shell river turtles (Chelodina expansa). J. Herpetol. 36: 304-307.

Díaz-Paniagua, C., Cuadrado, M. (2003): Influence of incubation conditions on hatching success, embryo development and hatchling phenotype of common chameleon (Chamaeleo chamaeleon) eggs. Amphibia-Reptilia 24 429-440.

Díaz-Paniagua, C., Cuadrado, M., Blázquez, M.C., Mateo, J.A. (2002): Reproduction of Chamaeleo chamaeleon under different environmental conditions. Herpetol. J. 12: 99-104. 
Ewert, M.A. (1985): Embryology of turtles. In: Biology of the Reptilia, Vol. 14, p. 75-267. Gans, C., Billet, F., Maderson, P.F.A., Eds, New York, John Wiley and Sons.

Ewert, M.A. (1991): Cold torpor, diapause delayed hatching and aestivation in reptiles and birds. In: Egg Incubation: Its Effects on Embryonic Development in Birds and Reptiles, p. 173-191. Deeming, D.C., Ferguson, M.W.J., Eds, Cambridge, Cambridge University Press.

Ewert, M.A., Wilson, D.S. (1996): Seasonal variation of embryonic diapause in striped mud turtle (Kinosternon baurii) and general consideration for conservation planning. Chel. Cons. Biol. 2: 43-54.

Packard, G.C. (1991): Physiological and ecological importance of water to embryos of oviparous reptiles. In: Egg Incubation: Its Effects on Embryonic Development in Birds and Reptiles, p. 213-228. Deeming, D.C., Ferguson, M.W.J., Eds, Cambridge, Cambridge University Press.
Packard, G.C., Packard, M.J. (1988): The physiological ecology of reptilian eggs and embryos. In: Biology of the Reptilia, Vol. 16, p. 523-605. Gans, C., Huey, R.B., Eds, New York, Alan R. Liss.

Packard, G.C., Packard, M.J., Miller, K., Boardman, T.J. (1987): Influence of moisture, temperature and substrate on Snapping turtle eggs and embryos. Ecology 68: 983 993.

Thompson, M.B., Packard, G.C., Packard, M.J., Rose, B. (1996): Analysis of the nest environment of tuatara Sphenodon punctatus. J. Zool., Lond. 238: 239-251.

Received: October 18, 2006. Accepted: January 11, 2007. 